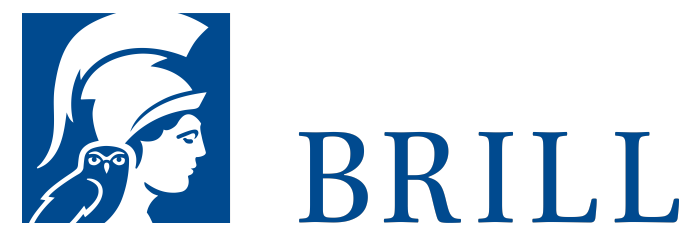

\title{
Zwischen Autonomie und Natürlichkeit
}

Der Begriff der Authentizität und die bioethische Debatte um das Neuro-Enhancement

Author: Jon Leefmann

Hat die subjektive Erfahrung, uns selbst und anderen als eine bestimmte Person zu erscheinen, eine ethische Orientierungsfunktion? Und wenn ja, was geschieht, wenn wir uns auf eine Weise verändern, die uns an der Kontinuität dieser Erfahrung zweifeln lässt? Ausgehend von Schilderungen von Nicht-Authentizitäts-Erfahrungen wird in diesem Buch der Versuch unternommen, einen Begriff personaler Authentizität zu rekonstruieren, der für Fragen der angewandten Ethik handhabbar ist. Dabei verbindet das Buch auf innovative Weise zwei Diskussionsstränge aus der Bioethik und der praktischen Philosophie: die bioethische Diskussion um das NeuroEnhancement und die Debatte um das richtige Verständnis »personaler Autonomie« in der analytischen Philosophie. Dieser Ansatz erlaubt zu zeigen, dass der Begriff der Authentizität nicht im Begriff der Autonomie aufgeht und dass ersterer für die angewandte Ethik am besten als eine Fähigkeit zu rekonstruieren ist. Dadurch kann nicht nur die Bedeutung von Selbstwissen für eine verantwortungsvolle technische Selbstgestaltung thematisiert, sondern auch die in der Enhancement-Debatte häufig stiefmütterlich behandelte Perspektive des guten Lebens hervorgehoben werden.

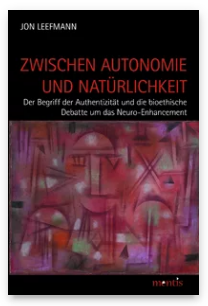

Pages: 381

Seiten

Language:

German

Subjects:

General, Philosophy

Publisher: Brill | mentis

E-Book (PDF)

Released online: o1 Apr 2017

ISBN: 978-395743-881-2

List price

Paperback

Publication date: o1 Apr 2017

ISBN: 978-395743-o66-3

List price 
For more information see brill.com

Order information: Order online at brill.com +44330 333 0049 | customerservices@brill.com Submission information: brill.com/authors

Titles published by Brill | Fink, Brill | mentis or Brill | Schöningh: +49(o)715413279216| brill@brocom.de 